\section{Dental therapy in the United Kingdom: part 2. A survey of reported working practices}

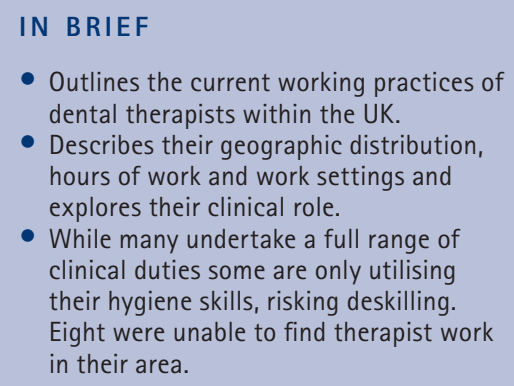

\author{
J. H. Godson, ${ }^{1}$ S. A. Williams, ${ }^{2}$ J. I. Csikar, ${ }^{3}$ S. Bradley ${ }^{4}$
}

and J. S. Rowbotham ${ }^{5}$

\begin{abstract}
Objectives To conduct a survey of current working practices of UK dental therapists following the changes in permitted duties, allowed clinical settings and the introduction of the new dental contract in England and Wales. Methods A piloted postal questionnaire was circulated in 2006 to all General Dental Council (GDC) registered therapists and those on the hygienists register possessing a dental therapy qualification. Two subsequent mailings were used to boost the response rate. Results There was an $80.6 \%$ response rate $(n=587)$. Ninety-eight percent of respondents were female. Average time since qualification was 17 years. Eighty percent $(n=470)$ of respondents were currently working as a dental therapist, 53\% parttime. Of the 470, half were engaged entirely in general dental practice (GDP), one third in the salaried dental services (SDS), while others worked across different settings. Only 39\% claimed to spend most of their time treating children. Recently qualified therapists more often worked in GDP $(p<0.001)$. Overall, a wide range of clinical duties were performed, although there was concern about maintaining skills across all the competencies since qualification, while emphasis on hygiene work was a limiting factor for some. On the basis of the continued professional development (CPD) activities described over one year, only half would have met the GDC CPD requirements from August 2008 for dental care professionals (DCPs). Conclusions More than half of therapists now work in GDP, compared with none six years previously. Many undertake a full range of duties. However, there was concern that some dentists use them for hygiene skills rather than across the whole range of their competencies, risking deskilling, while others reported their inability to gain employment as a therapist.
\end{abstract}

\section{DENTAL THERAPY IN THE UNITED KINGDOM \\ 1. Development in therapists' training and role \\ 2. A survey of reported working practices \\ 3. Financial aspects of current working practices \\ 4. Teamwork - is it working for dental therapists?}

${ }^{1}$ Honorary Lecturer, Dental Public Health, Leeds Dental Institute/Consultant in Dental Public Health, NHS Bradford and Airedale, Douglas Mill, Bowling Old Lane, Bradford, BD5 7JR; ${ }^{2}$ Emeritus Professor in Oral Health Services Research, Dental Public Health, Leeds Dental Institute, Clarendon Way, Leeds, LS2 9LU; ${ }^{3^{*}}$ Researcher Dental Public Health, Leeds Dental Institute/Senior Public Health Manager, NHS Bradford and Airedale, Douglas Mill, Bowling Old Lane, Bradford, BD5 7JR; ${ }^{4}$ General Dental Practitioner/PCT Dental Adviser, Primecare Oral Health Services, Bedale Health Centre, Sussex Street, Bedale, North Yorkshire, DL8 2AH: ${ }^{5}$ Dental Therapist/Principal Tutor, Programme of Dental Hygiene and Dental Therapy, Leeds Dental Institute, Clarendon Way, Leeds, LS2 9LU

*Correspondence to: Ms Julia Csika

Email: j.i.csikar@leeds.ac.uk

\section{Refereed Paper}

Accepted 8 April 2009

DOI: $110.1038 /$ sj.bdj.2009.962

${ }^{\oplus}$ British Dental Journal 2009; 207: 417-423

\section{INTRODUCTION}

Over the last five years, there have been major changes in the training, numbers recruited and regulations pertaining to the work of dental therapists. ${ }^{1}$ UK opportunities are rapidly expanding as schools and numbers in training increase. The range of treatment competencies taught has expanded. Since 2002, GDC regulations have enabled extension of the range of clinical activities or 'permitted duties' that can be performed by therapists, as long as they have received the appropriate training. ${ }^{2}$ The range of clinical settings allowed has also increased. Following the personal dental service (PDS) pilots in England, which were established to test alternative ways of delivering dental services (through local contracting arrangements) including the employment of dental therapists in dental practices, ${ }^{3}$ and the introduction of the new dental contract in England and Wales in 2006, therapists may now work in general dental practice as well as the salaried and hospital services to which they were previously limited. Therapists are now referred to under the term 'dental care professional' (DCP), which also includes dental hygienists, dental nurses, dental technicians, clinical dental technicians and orthodontic therapists, all of whom must now register as DCPs with the GDC.

Further clarification regarding the roles of DCPs was given by the GDC in 2009 in a document entitled Scope of practice, which details the skills that each DCP will have been trained to carry out and additional skills they may develop during their careers. Irrespective of whether a therapist has a diploma in dental therapy alone or combined with dental hygiene or a BSc, they will be trained and competent to carry out all the duties of a therapist in addition to those of a hygienist as described in Scope of practice. ${ }^{4}$

The extent to which dentists have seriously considered the possibility of adding dental therapists to their practice teams in the UK has changed over time. In 1982, $38 \%$ of GDPs indicated they would welcome the opportunity to employ a therapist. ${ }^{5}$ However by 2007, 43\% of dentists 


\begin{tabular}{|c|c|c|}
\hline Age group (years) & $\mathrm{n}$ & $\%$ \\
\hline $20-30$ & 139 & 24 \\
\hline $31-40$ & 126 & 22 \\
\hline $41-50$ & 185 & 31 \\
\hline $51-60$ & 114 & 19 \\
\hline $60+$ & 21 & 4 \\
\hline Missing value & 2 & 0 \\
\hline Total & 587 & 100 \\
\hline
\end{tabular}

(NHS and private) in Wales were prepared to consider employing therapists ${ }^{6}$ compared with 64\% in Southern Scotland. ${ }^{7}$ Recently qualified practitioners were more likely to favour delegation ${ }^{5}$ and to welcome the opportunity of employing therapists, ${ }^{5,8}$ as were those already working with a hygienist and/or operating in larger practices. ${ }^{7}$ However, recent studies of dentists' knowledge of the employment of dental therapists in Scotland ${ }^{7}$ and West Sussex ${ }^{9}$ reported that dentists lack knowledge of dental therapists clinical remit, the groups they can treat and level of supervision required.

The most recent published survey of working practices of UK dental therapists ${ }^{10}$ was conducted before recent developments, which now involve expansion into general dental practice, extended clinical duties and the new dental contract in England and Wales. This survey was conducted in order to ascertain the scope of work that therapists now undertake following the introduction of the new contract in England and Wales and other recent developments influencing the current practice of dental therapy.

This paper sets out the basic findings of the survey in terms of demographic profile, work settings, locations, hours of work, details of clinical practice, oral health promotion activity and Continuing Professional Development (CPD) of dental therapists. A secondary aim was to identify characteristics, including year of qualification, the clinical setting in which they worked and percentage of NHS work undertaken, that might be related to these responses and to collate any additional explanations provided from the open responses. Subsequent papers in the series will focus on finance and teamwork.

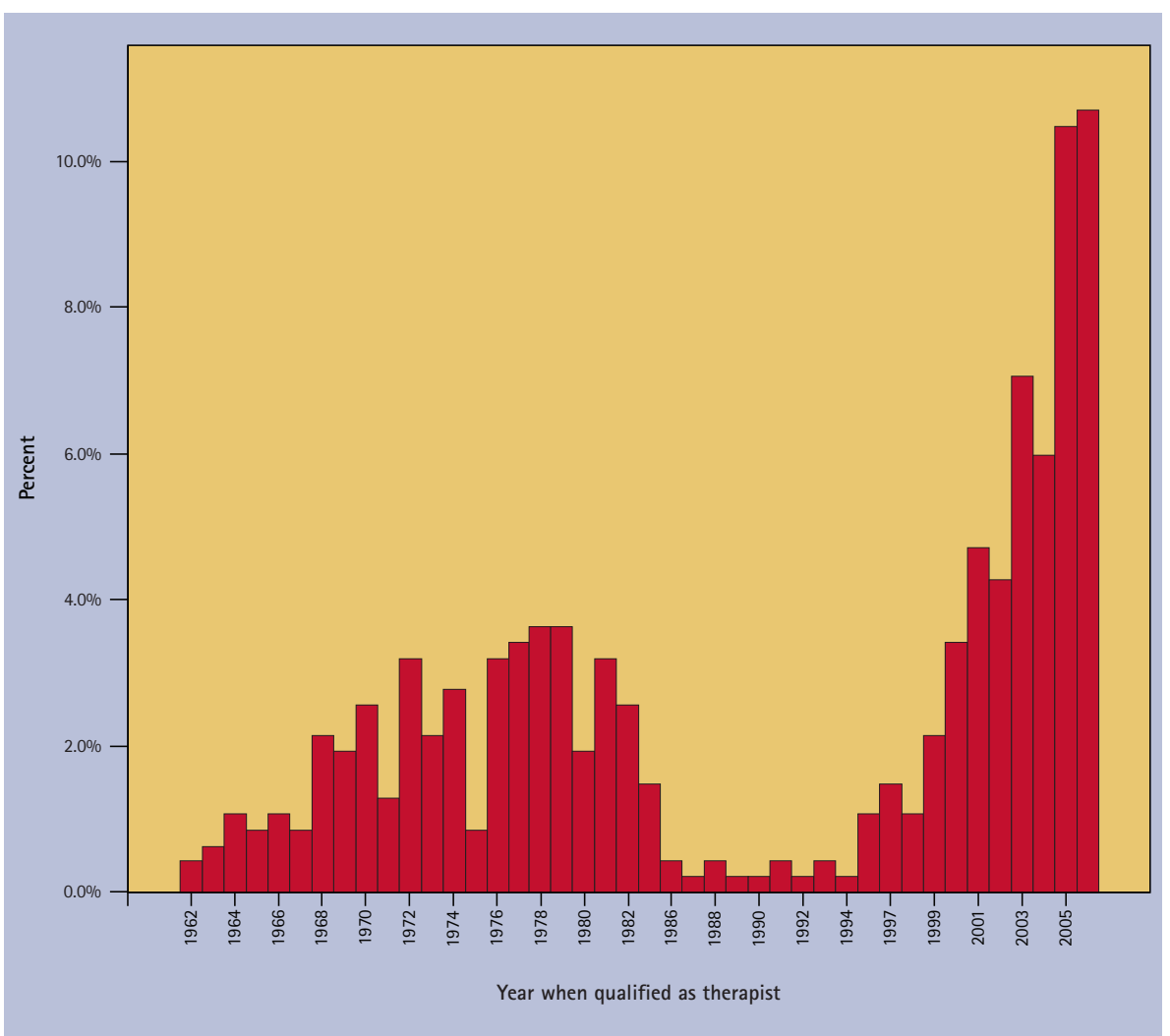

Fig. 1 Distribution of therapists who responded, according to year of qualification

Table 2 Geographic location of therapists who responded within the UK (England broken down by strategic health authority)

\begin{tabular}{l|l|l|l|}
\hline $\begin{array}{l}\text { Strategic health } \\
\text { authority (SHA) }\end{array}$ & No. of therapists (\%) & Population per dentist & $\begin{array}{l}\text { Population per } \\
\text { therapist (ranking) }\end{array}$ \\
\hline London & $57(11 \%)$ & 1,987 & $131,895(9)$ \\
\hline South East Coast & $47(9 \%)$ & 2,013 & $89,660(5)$ \\
\hline South Central & $54(11 \%)$ & 2,232 & $73,148(1)$ \\
\hline East of England & $45(9 \%)$ & 2,234 & $123,155(7)$ \\
\hline South West & $41(8 \%)$ & 2,247 & $123,610(8)$ \\
\hline North West & $82(16 \%)$ & 2,318 & $83,488(3)$ \\
\hline North East & $13(3 \%)$ & 2,506 & $196,769(10)$ \\
\hline York \& Humber & $61(12 \%)$ & 2,573 & $83,016(2)$ \\
\hline East Midlands & $50(10 \%)$ & 2,616 & $86,120(4)$ \\
\hline West Midlands & $47(9 \%)$ & 2,620 & $114,149(6)$ \\
\hline Total & $497(100 \%)$ & 2,414 & 101,473 \\
\hline Coun & & &
\end{tabular}

\section{Country}

\begin{tabular}{|c|c|c|c|}
\hline England & $497(86 \%)$ & 2,414 & 101,473 \\
\hline Wales & $46(8 \%)$ & 2,584 & 64,209 \\
\hline Scotland & $30(5 \%)$ & 2,704 & 169,827 \\
\hline Northern Ireland & $7(1 \%)$ & 2,287 & 246,343 \\
\hline \multicolumn{4}{|c|}{$\begin{array}{l}\text { Notes: England, Wales and SHA data, population data ONS } 2005 \text { mid-year population estimates based on } 2001 \text { census } \\
\text { England number of dentists (performerss BSA data } 31 \text { December } 2006 \\
\text { Welsh number of dentists - Wales Assembly Government statistics Wales } 31 \text { December } 2006 \\
\text { Scotland number of dentists - Scottish health statistics ISD Scotland } 31 \text { March } 2004 \\
\text { Northern Ireland number of dentists - Northern Ireland Statistics and Research agency April } 2006 \\
\text { Dentists may be counted more than once if they have contracts in more than one SHA/health board }\end{array}$} \\
\hline
\end{tabular}




\section{MATERIALS AND METHODS}

The sample was identified as all therapists on the GDC list and therapists on the hygienist register (identified by stated qualification in dental therapy) in June 2006. At that time, the GDC held separate rolls for each group, although this has now been superseded by a register for all DCPs. Thus participants would all be qualified as dental therapists. Of these, some would also be qualified as hygienists, although they might only have opted to register to practice as hygienists at that time. A postal questionnaire survey was carried out between September 2006 and January 2007.

The semi-structured questionnaire addressed topic areas which had been covered in previous surveys and included demographic profile, sector of practice, type of work and patients seen, remuneration method and CPD. The respondents were asked to clarify their answers to closed questions with free text open responses to obtain a qualitative perspective regarding their work as a dental therapist. The questionnaire was piloted with a group of dental therapists and amendments made to wording and layout.

The questionnaire, covering letter and reply paid envelope were sent to each identified participant. Two subsequent mailings were also carried out at four week intervals to improve response rates. The quantitative data were coded and entered into the Statistical Package for the Social Sciences (SPSS version 12.1). Questionnaires with responses to less than 90\% of applicable questions were excluded from the analysis. If single items were missing the respondent was excluded for that item only. The quantitative data were examined in stages, firstly describing the sample according to the variables, using univariate analysis on working patterns and multivariate analysis to assess whether the setting therapists worked in, the proportion of time spent working in the NHS and years since qualification affected the range of clinical duties performed. The threshold for statistical significance adopted was the 5\% level.

The open responses were transcribed and organised into themes and sub-themes. Any illustrative quotes used were put in the context of the overall responses, ie when they reflected a majority/minority view this was stated in the text. The validity of the open responses was cross checked by comparison with the relevant quantitative response.

\section{RESULTS}

\section{Response rate}

Of the original sampling frame of 816, 36 were not known at the address given and two were existing students, resulting in a revised sampling frame of 778 . After three mailings the total number of responders was 627 (80.6\%). Of the 627 who responded, 40 were not actively working or were not working in the field of dentistry $(n=2)$ leaving a total sample of 587.

\section{Qualitative themes}

The qualitative information arising was substantial, with information provided consisting of approximately 500 separate responses. The most frequent themes identified from the semi-structured and open text responses were current working practices (104), followed by extended duties (53) and CPD (32). Examples of responses reflecting the quantitative findings have been used throughout the paper.

\section{Profile of responders}

Of the 587 dental therapists who responded, $98 \%(\mathrm{n}=573$ ) were female, the majority aged between $41-50$ years (31\%) with $24 \%$ aged 20-30 years (Table 1). Of the 41-50 year group, 69\% had trained at New Cross. Of the 154 therapists who originally trained at New Cross, 59 (38\%) had gone on to obtain additional hygienist qualifications. The average time since qualification was 16.9 years (SD 14.2 years) with peaks in qualification in the 1970 s and post-2000 (Fig. 1).

\section{Geographic distribution}

The location of dental therapists was assigned according to the postcode of their registered address (Table 2). Of those who responded, the majority were based in England ( $\mathrm{n}=497,86 \%$ ) with $8 \%$ in Wales, 5\% Scotland and 1\% in Northern Ireland. Within England the largest number ( $\mathrm{n}=82,16 \%$ ) were located in the North West Strategic Health Authority (SHA). The distribution of therapists was examined in relation to dentist and therapist population ratios (Table 2). Inequalities in provision were identified between countries and

\begin{tabular}{|c|c|c|}
\hline Working setting & Number & Percent \\
\hline GDP only & 228 & $50 \%$ \\
\hline SDS only & 140 & $30 \%$ \\
\hline Hospital only & 16 & $3 \%$ \\
\hline Teaching only & 2 & $<1 \%$ \\
\hline GDP \& SDS & 45 & $10 \%$ \\
\hline GDP \& hospital & 14 & $3 \%$ \\
\hline GDP \& tutor & 1 & $<1 \%$ \\
\hline SDS \& hospital & 9 & $2 \%$ \\
\hline GDP \& SDS \& hospital & 3 & $<1 \%$ \\
\hline NR & 12 & \\
\hline
\end{tabular}

according to SHA within England. SHAs with below average provision for England as a whole for either dentists or therapists had above average provision for the alternate service provider apart from the North East and West Midlands, which had lower than average England provision for both dentists and therapists. In contrast, North West, South East Coast and South Central SHAs had above average provision for England of both dentists and therapists.

\section{Current working practice of all responders}

The majority of respondents reported that they were currently working as a dental therapist ( $\mathrm{n}=470,80 \%)$. Of the 117 'not working as a dental therapist', the majority (91\%) claimed to be either 'entirely limited to dental hygiene' or involved in 'other dental work'. Twenty-three respondents were GDC registered as hygienists but not as therapists. Eight stated that they could not find therapist work in their locality. Of those not currently working as a dental therapist, half of those responding felt disinclined to return to working as a therapist in the future. The main reasons offered were that they now worked as a hygienist, while some mentioned that they lacked confidence to return to dental therapy and/ or needed a refresher course.

Further analysis was restricted to the 470 dental therapists (all registered with the GDC as dental therapists) who claimed to be currently working as a therapist either full- or part-time. 


\section{Work settings}

Of those currently working as a therapist, half worked in general dental practice $(50 \%, n=228)$ with $31 \%(n=140)$ in the salaried primary dental services (SDS) and a further 10\% combining work in both (Table 3). The remainder worked in the hospital services or as a tutor or in combination.

The work setting was assessed according to years since qualification. Those in GDP were more likely to be recently qualified (71\% qualified for 10 years or less) compared with those working only in the SDS (20\% qualified less than 10 years) ( $p<0.001)$.

Dental therapy offered variety, since the majority (63\%) reported that they worked at more than one location and $8 \%$ worked in four or more sites (Fig. 2). There was no difference in the number of locations worked between those only in GDP and those only in the SDS.

\section{Hours of work}

The average hours per week worked by therapists was 25.3 hours (range 0.5-45 hours). Over half (53\%) worked part-time, considered as less than 30 hours per week. The distribution of working hours is shown in Figure 3. The part-time nature of the work and the variety it offered were appreciated by some:

'Currently I work 21/2 days per week due to family commitments. I work one day in the community dental services as a dental therapist. 11/2 days in practice as a hygienist. I feel that way my work is varied and I do enjoy both hygiene and therapy work'

\section{Treating children}

Of the 470 dental therapists, 39\% claimed that they spent most of their time treating children. Of this group 54\% were New Cross-trained therapists, compared with $38 \%$ who trained elsewhere $(p<0.001)$. However, New Cross-trained therapists who had also acquired additional hygienist qualifications did not behave any differently to the rest of that group in respect of treating children. Those spending most of their time treating children were more likely to have been qualified in dental therapy for the longest, spent $100 \%$ of their time on NHS work and to work in the SDS. In contrast, those seeing the lowest proportion of children had

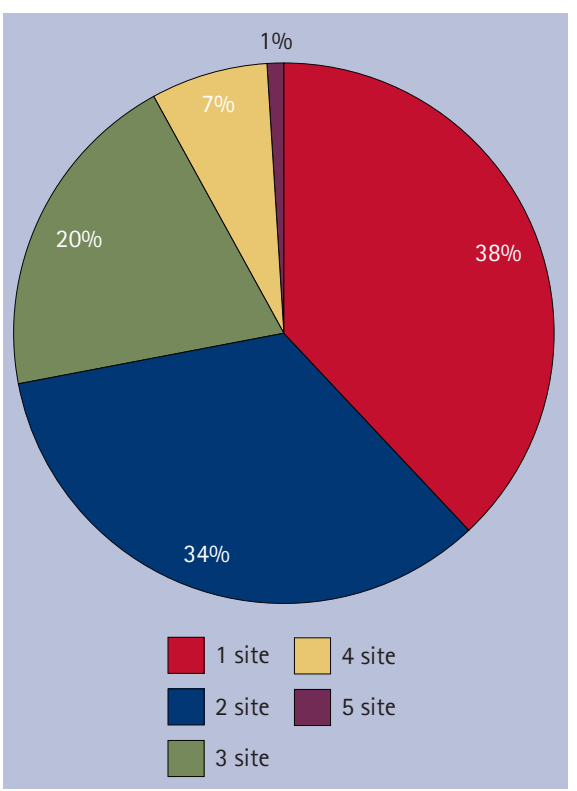

Fig. 2 Number of sites where dental therapists work

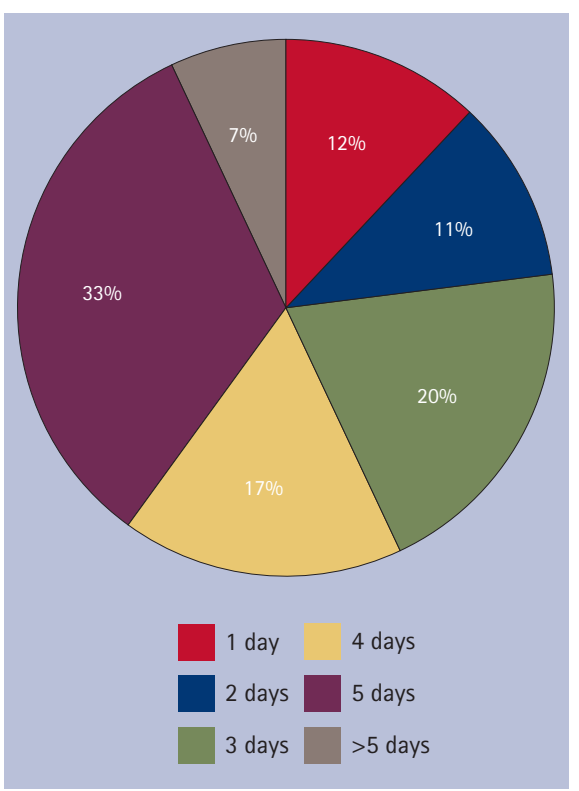

Fig. 3 Number of days worked by dental therapists ( 1 day $=7.5$ hours)

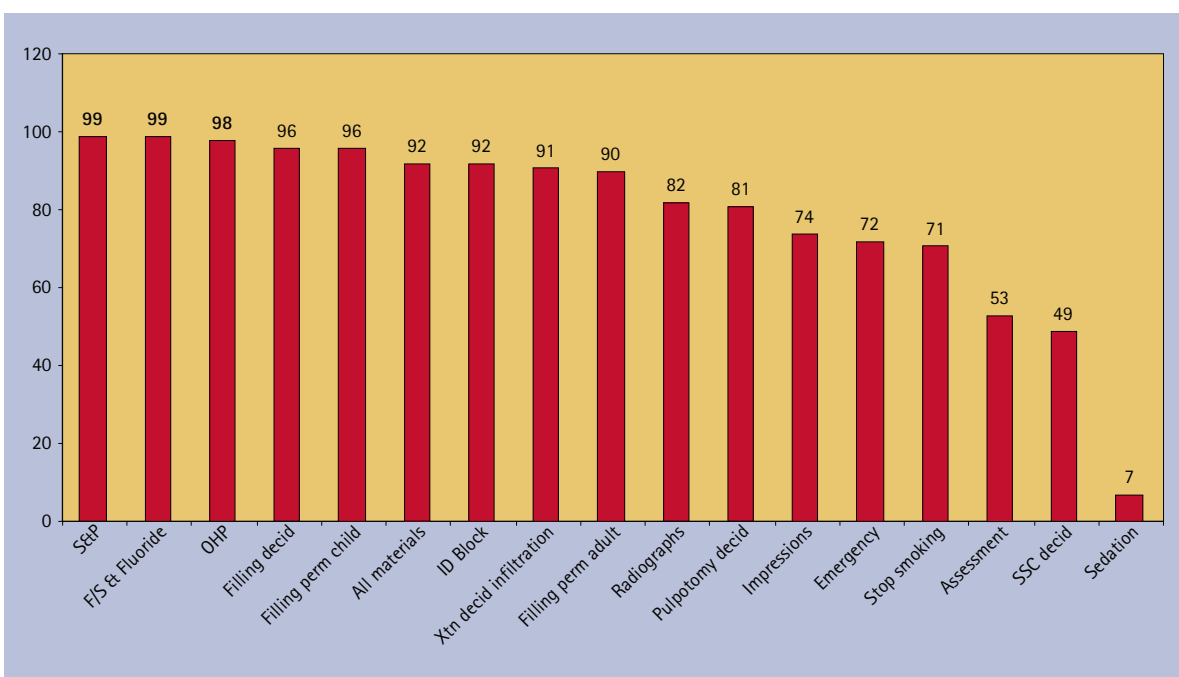

Fig. 4 Percentage of therapists carrying out various procedures

qualified in dental therapy most recently (2004-2006), worked mainly in the private sector (0-8\% NHS) and in a GDP setting. These differences were all highly significant ( $p<0.001)$.

\section{Percentage of NHS work undertaken}

Respondents $(\mathrm{n}=470)$ were asked to state what proportion of their work was NHS-related in terms of clinical time. Approximately one third (36\%) worked $100 \%$ under NHS regulations, whereas a further 32\% spent the majority of their time on NHS (NHS 50-99\%) work. The remaining 32\% were mainly involved with private work, with $13 \%$ spending $<10 \%$ of their time with NHS activities. Those therapists who qualified more recently (since
1997) were significantly more likely to undertake a higher proportion of private work ( $p<0.001)$.

\section{Clinical duties}

Of the 470 therapists currently working full or part time as a dental therapist, 105 stated that they currently performed the majority of clinical duties corresponding to those of a hygienist. Of this group ( $\mathrm{n}=105)$, two thirds were in GDP, while a few worked in combination with SDS or hospital services. Three therapists also worked as a dental nurse but always in combination with their therapy and hygiene roles. This nursing role was confined to the SDS. Out of 104 free text responses regarding current working practices, the majority of views reflected the exclusive or nearly exclusive 
emphasis on hygiene work $(n=49)$ and lack of job opportunities $(\mathrm{n}=28)$ :

'I find it frustrating. I do the majority of my clinical time working on hygiene.'

'Mostly do hygiene work and find it very disappointing that hardly any therapist positions are available. Can't understand why so many therapists are currently being trained.'

'I would like to do more days with therapy but find that dentists are only interested in hygiene.'

'Why is it so difficult to find a job as a therapist? It is not fair! We are qualified to do a lot but because there aren't many jobs available, we have to work as hygienists!'

Twenty-six responses elaborated on the lack of confidence resulting from an inability to practice previously learned skills:

'I don't really carry out much of the work I was trained to do as a therapist. I ... spend almost all of my working time doing hygiene work... I have lost my confidence to do fillings as I haven't done enough since qualifying.'

Since 2002 all newly qualified dental therapists have been trained to carry out an increased range of duties. Of those GDC registered therapists who qualified before this date $(\mathrm{n}=376)$, the majority $(86 \%)$ claimed to have received additional training to enable them to carry out this full range of duties.

Those currently working as therapists ( $n=470$ ) were asked about the range of duties they carry out (Fig. 4). Over 90\% of therapists stated that they performed nine common procedures (scale and polish; fissure sealants/fluoride application; oral health promotion (OHP) in the surgery; restoring primary teeth; restoring permanent teeth in children; using all materials; administering ID block; extracting primary teeth; restoring adult teeth). However, a lower proportion took radiographs (82\%), performed pulpotomies (81\%) and emergency replacement of crowns and fillings (72\%), took impressions (74\%), gave smoking cessation advice (71\%), undertook oral assessments (53\%), fitted stainless steel crowns (49\%) and treated patients under

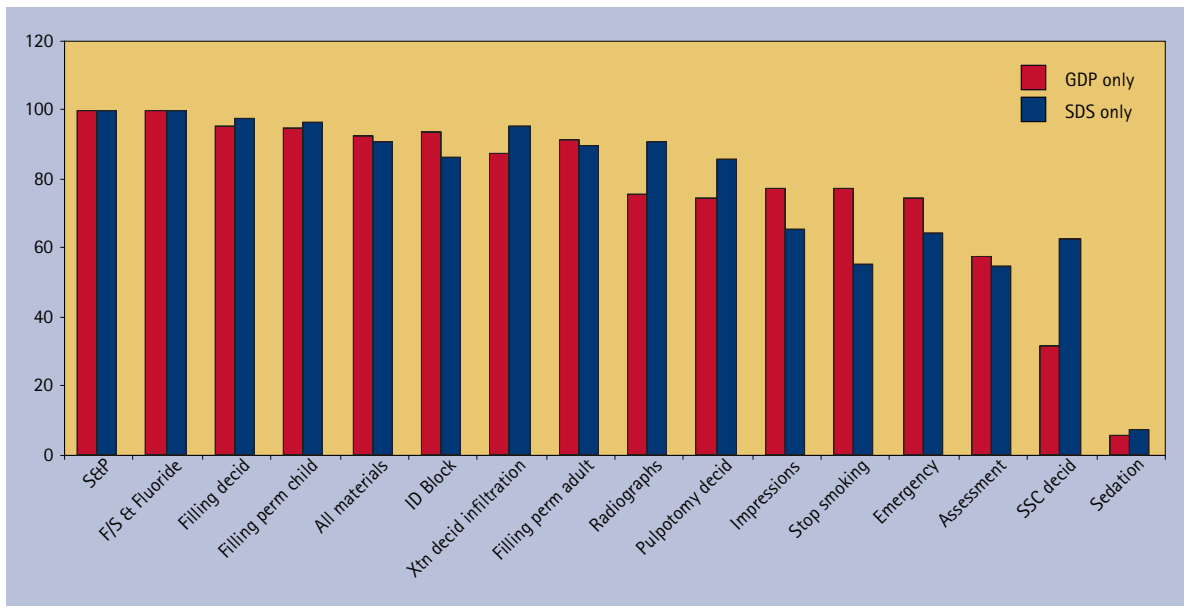

Fig. 5 Percentage of therapists carrying out procedures, according to work setting

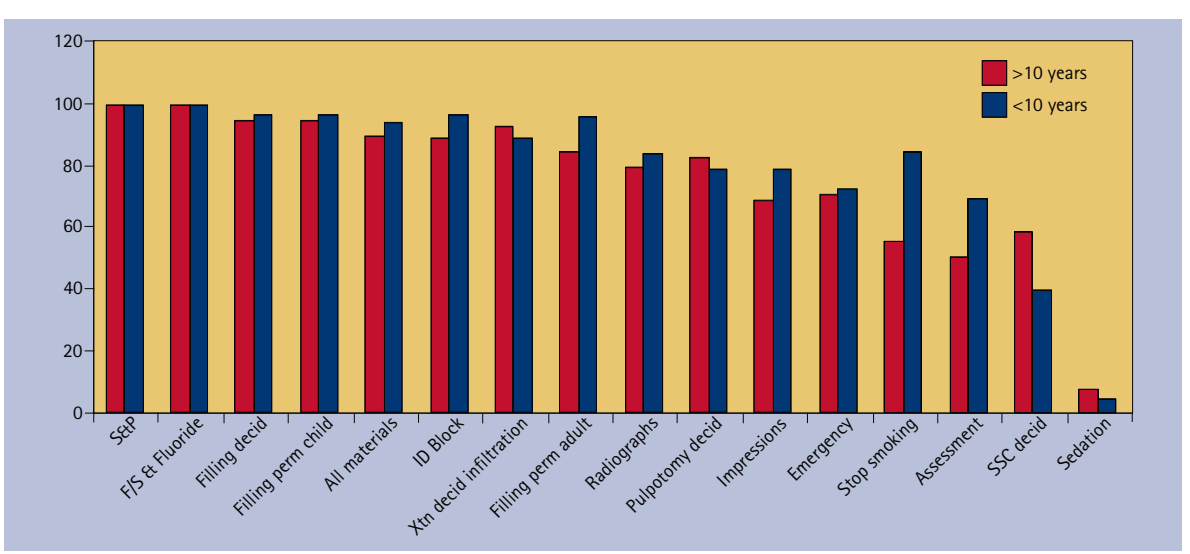

Fig. 6 Percentage of therapists carrying out procedures, according to years qualified

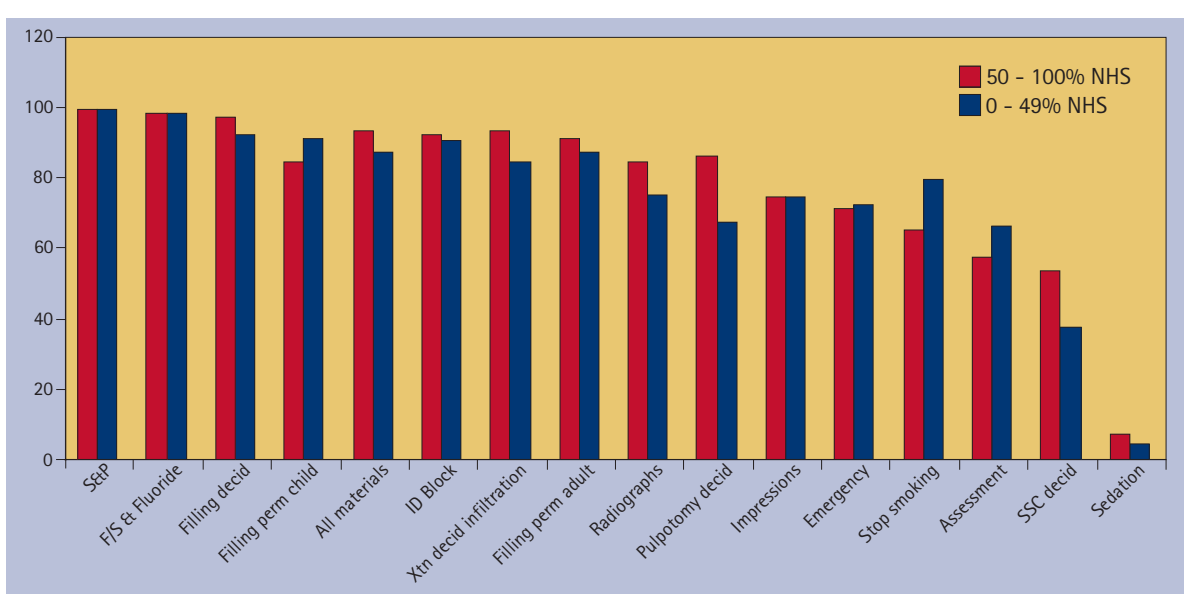

Fig. 7 Percentage of therapists carrying out procedures, according to the percentage of their time spent on NHS work

conscious sedation (7\%). Responses supported the challenge in maintaining all these skills in a working environment ( $\mathrm{n}=27$ ):

'It is hard for us to regularly do all the procedures and then you lose confidence. I need to routinely carry out procedures to be clinically excellent.'

I have never treated anyone under conscious sedation. I think this is a waste of a duty as a dentist has to be in the same room while carrying out treatment. Not very cost effective so it doesn't happen.'

Duties carried out were described according to the clinical practice setting: either GDP or salaried services (Fig. 5). They were also compared according to years qualified (Fig. 6) and NHS commitment (Fig. 7).

In order to avoid confounders that can distort interpretation of findings when 


\begin{tabular}{|c|c|c|c|c|c|c|c|c|}
\hline Independent variables & $\begin{array}{l}\text { Stainless } \\
\text { steel crown }\end{array}$ & ID block & Pulpotomy & $\begin{array}{l}\text { Deciduous } \\
\text { extractions }\end{array}$ & Radiograph & $\begin{array}{l}\text { Deciduous } \\
\text { filling: child }\end{array}$ & $\begin{array}{l}\text { Intra-oral } \\
\text { assessment }\end{array}$ & $\begin{array}{l}\text { Stop smoking } \\
\text { advice }\end{array}$ \\
\hline 100\% NHS employment (no/yes) & NS & NS & NS & NS & NS & NS & NS & NS \\
\hline Qualified < 10 years ago (no/yes) & NS & $\begin{array}{l}3.8^{*} \\
(1.7-8.5)\end{array}$ & NS & NS & $\begin{array}{l}2.3^{*} \\
(1.3-4.0)\end{array}$ & $\begin{array}{l}3.1^{*} \\
(1.1-8.7)\end{array}$ & $\begin{array}{l}2.6^{*} \\
(1.7-4.0)\end{array}$ & $\begin{array}{l}3.6^{*} \\
(2.3-5.7)\end{array}$ \\
\hline Working in SDS only (no/yes) & NS & NS & NS & $\begin{array}{l}3.8^{*} \\
(1.3-11.0)\end{array}$ & $\begin{array}{l}2.5^{*} \\
(1.1-5.8)\end{array}$ & $\begin{array}{l}4.8^{*} \\
(1.04-22.2)\end{array}$ & $\begin{array}{l}0.5^{*} \\
(0.3-0.9)\end{array}$ & NS \\
\hline Working in GDP only (no/yes) & $\begin{array}{l}0.3^{*} \\
(0.2-0.4)\end{array}$ & NS & $\begin{array}{l}0.5^{*} \\
(0.3-0.8)\end{array}$ & NS & $\begin{array}{l}0.5^{*} \\
(0.3-0.98)\end{array}$ & NS & $\begin{array}{l}0.4^{*} \\
(0.3-0.8)\end{array}$ & NS \\
\hline
\end{tabular}

simple univariate analyses are performed, the most important predictors for each specific clinical duty (the dependent variable) were assessed in turn using multivariate analysis with binary logistic regression. In each case, the independent dichotomised variables were $100 \%$ time on NHS treatment, qualified less than 10 years, working only for the SDS, working only in GDP. Table 4 shows the results for those duties including where a significant outcome was established.

As can be seen from Table 4:

- Those working only in GDP were less

likely to provide extra-/intra-oral assessments, stainless steel crowns, pulpotomies or radiographs

- Compared with those who had been qualified longer, recently qualified therapists were more likely to provide an extra-/intra-oral assessment, radiographs, ID blocks and deciduous restorations as well as smoking cessation advice

- Those working in the SDS only were less likely to provide extra-/intra-oral assessment, but more likely to take radiographs and undertake deciduous restorations and extractions.

\section{Continuing professional development}

All GDC registered therapists were asked about their CPD activities in the last year. Of the 470 respondents, $83 \%$ claimed to have taken part in CPD activities, 78\% attended a course, 74\% read journals and 26\% used computer aided learning programmes. Only half would have met the new GDC requirement of 30 hours CPD for DCPs in the last 12 month period.

Responses within the theme of CPD addressed the perceived lack of opportunities to attend CPD courses ( $n=14$ ) either because they were geographically distant, none were available, or due to lack of funds. Several respondents also thought that DCPs should access CPD courses alongside dentists:

'Need more CPD courses for dental therapists to attend alongside dentists. Most courses are for dental therapists/dental hygienists - and usually involve a lot of travel.'

'Would like to access the same courses as dentists.'

'There is a lack of opportunity for me to return to therapy work. A lack of handson courses.'

'PCTs do not fund CPD courses for dental therapists - yet CPD will be compulsory in 2008.'

\section{DISCUSSION}

This paper reports the findings of a survey with a response rate of over $80 \%$. The results can therefore be accepted as reasonably representative of UK-based therapists. A large volume of explanatory text was provided by most respondents to the semistructured and open questions. The number and length of these may be interpreted as testimony to the strength of their views but might also be considered as a potential source of bias on account of an inherently differential response. Clearly a carefully designed qualitative study is required to substantiate and further explore the issues identified here.

The average age of dental therapists and years since qualification reflect the history of training in the UK, with peaks in the 1970s and post-2000. The distribution of therapists throughout the UK varied, with
South Central, Yorkshire \& Humberside and North West SHAs being best served and the North East least served. In contrast, in 1980 Holt and Murray ${ }^{11}$ found South East Thames to be best served and Mersey and the North the least. Clearly, there has been a marked redistribution since then, although the North East, as an area of deprivation, remains relatively underserved by therapists and dentists alike. The Nuffield Report ${ }^{12}$ commented on the desirability for therapists to be working in areas of greatest need, where access is lowest and disease levels higher. However, it was also noted that the provision of therapists in an untargeted way, left to market forces, might not serve to reduce health inequalities. In this survey, one third of therapists were working in practices where more than 50\% of clinical time involved private work, indicating that this trend may be occurring.

In 2000, the previous survey of dental therapists involved 304 therapists (with an $80 \%$ response rate) compared with 470 in the present study, thus reflecting the increasing numbers of therapists on the register. At that time, 205 (93\% of the study sample) worked in the SDS, with a significant proportion treating children. The present study showed that similar numbers (197 therapists, 42\%) worked at least part of their clinical time in the SDS. Interestingly, this group was represented by those who had mainly been qualified before 1997. GDP now involved $50 \%$ of the sample as the only source of work and had attracted more recently qualified therapists. The majority of therapists no longer spend most of their time treating children.

The study used a sampling frame from two separate GDC registers, although these 
are no longer available with DCPs now making one single registration payment instead. The previous system provided an opportunity to establish that $80 \%$ of those with dental therapy qualifications felt that they were spending part or all of their time on therapy duties. It also indicated that a proportion of previously qualified therapists were now working as hygienists, although some were happy with that situation. The previous study ${ }^{10}$ also noted that $60 \%(n=46)$ of those not currently working as a therapist were working as a hygienist, so this is a long-standing issue. However, this survey also noted concerns about deskilling resulting from the perceived lack of opportunities to undertake the full range of therapy duties, an issue also raised in a recent paper. ${ }^{13}$

The majority of therapists work at more than one site, even though 53\% work part-time. The proportion working part-time was identical to that found in $2000 .{ }^{10}$ Childcare responsibilities have been linked to part-time working, as were career breaks, ${ }^{10}$ whereas this study also identified frustration at being unable to find therapy posts locally.

In 1993 the most popular predicted role for therapists was an equal division between provision of dental care and dental health education. ${ }^{8}$ Therapists must work to the written prescription of a dentist and the findings of several studies ${ }^{7,9}$ have illustrated that many dentists were vague about this remit. While knowledge of the therapist's role concerning treatment of children was good, this was not true for adults. Ross et al. ${ }^{7}$ reported that only $25 \%$ of dentists knew that therapists are able to undertake multisurface restorations for adults and 60\% incorrectly thought that they could only work if a dentist was on the premises - all of which may contribute to lack of employment prospects.

The range of permitted clinical duties has changed since the previous survey, which had noted that the majority of respondents had clinical responsibilities involving 'simple fillings', fissure sealants, dental health education and temporary dressings. ${ }^{10}$ The present study enquired about which duties are being undertaken that therapists are currently trained to perform. While nine of the 15 listed duties were carried out by at least 90\% of respondents, few were involved with sedation. Further analysis illustrated that those who qualified more recently were more likely to undertake oral health assessments, take radiographs, administer ID blocks, give smoking cessation advice and restore deciduous teeth, while those working in general dental practice were least likely to insert stainless steel crowns, take radiographs or perform pulpotomies and oral health assessments. However, this study only enquired about the range of clinical duties rather than the frequency with which they were performed. In order to address the issue of deskilling, further research is required to examine this in more detail. Clearly there are implications for retraining and for confidence-building, as well as for the provision of a wider range of opportunities to prevent deskilling occurring in the first place, where possible.

The majority of therapists claimed to have taken part in CPD activities in the past year. However, only 50\% would have met the GDC average requirement that from August 2008 DCPs should complete 30 hours of CPD per annum. Respondents and other authors ${ }^{14}$ have commented on the lack of access to courses due to them being geographically distant or the lack of funding to attend. There is a clear need to further develop suitable CPD programmes for the dental team in each deanery, combining where appropriate with some of those currently available only to dentists.

Where there is a dental manpower shortage and dental care is commissioned locally, the employment of dental therapists within GDP may now become more attractive to providers of dental care. However, until dentists or dental providers fully understand the advantages of integrating dental therapists into the dental team so that they can use their clinical skills to their full potential, therapists are likely to continue to find limited employment opportunities.

\section{CONCLUSION}

More than half of therapists now work entirely in general dental practice, compared with none six years previously. Many undertake a full range of duties. However, there was concern that dentists may use them for hygiene skills rather than across the whole range of their competencies, risking deskilling, while others reported their inability to gain employment as a therapist.

This project was funded by NHS RAD in Primary Dental Care.

1. Rowbotham J S, Godson J H, Williams S A, Csikar J I, Bradley S. Dental therapy in the United Kingdom: part 1. Developments in therapists' training and role. Br Dent J 2009; 207: 355-359.

2. General Dental Council. Developing the dental team. Curricula frameworks for registerable qualifications for professionals complementary to dentistry (PCDs). London: General Dental Council, 2004.

3. Harris R, Burnside $G$. The role of dental therapists working in four personal dental service pilots: type of patients seen, work undertaken and cost-effectiveness within the context of the dental practice. Br Dent J 2004: 197: 491-496.

4. General Dental Council. Scope of practice. London: General Dental Council, 2009.

5. Woolgrove J, Harris R. Attitudes of dentists towards delegation. Br Dent J 1982; 153: 339-340.

6. Jones G, Devalia R, Hunter L. Attitudes of general dental practitioners in Wales towards employing dental hygienist-therapists. Br Dent J 2007; 203: E19.

7. Ross M K, Ibbetson R J, Turner S. The acceptability of dually-qualified dental hygienist-therapists to general dental practitioners in South-East Scotland. Br Dent J 2007; 202: E8.

8. Hay I S, Batchelor P A. The future role of dental therapists in the UK: a survey of district dental officers and general dental practitioners in England and Wales. Br Dent J 1993; 175: 61-65.

9. Gallagher J L, Wright D A. General dental practitioners' knowledge of and attitude towards the employment of dental therapists in general practice. Br Dent J 2002; 194: 37-41.

10. Gibbons D, Corrigan M, Newton J T. The working practices and job satisfaction of dental therapists: findings of a national survey. Br Dent J 2000: 189: $435-438$

11. Holt R D, Murray J J. An evaluation of the role of New Cross dental auxiliaries and of their clinical contributionto the community dental service. Br Dent J 1980; 149: 259-262

12. The Nuffield Institute. The education and training of personnel auxiliary to dentistry. London: The Nuffield Institute, 1993.

13. Jones $G$, Devalia $R$, Hunter L. A survey of the workload of dental therapists/hygienist-therapists employed in primary care settings. Br Dent J 2008; 204: E5.

14. Ward P. The changing skill mix - experiences on the introduction of the dental therapist into general dental practice. Br Dent J 2006; 200: 193-197. 